\title{
A European approach to irritable bowel syndrome management
}

\author{
Michel Delvaux MD PhD, Jacques Frexinos MD
}

\begin{abstract}
M Delvaux, J Frexinos. A European approach to irritable bowel syndrome management. Can J Gastroenterol 1999;13(Suppl A): 85A-88A. Irritable bowel syndrome (IBS) is characterized by a number of clinical features and probably comprises a cluster of different conditions. The most frequent symptom reported by IBS patients is abdominal pain, although for a number of patients, bowel disturbances are the most prominent symptoms. Diarrhetic patients are seen in referral centres in continental Europe less frequently than in the United Kingdom or the United States. On the contrary, patients with constipation-prone IBS may comprise up to $80 \%$ of the IBS population referred to these centres. The pathophysiology of IBS is based on multiple factors. Most of the therapeutics proposed for the management of patients with IBS have been developed on the assumption that motility disorders of the gut are the most reliable pathological findings among these patients. Consequently, antispasmodics and motility regulatory agents have been widely used, alone or in association with intestinal adsorbents (clay-derived preparations), and laxatives or antidiarrhetic agents. Most of these drugs were developed several decades ago, and studies showing their efficacy have not reached the level of quality that is now required of randomized controlled trials. Therefore, following a complete and detailed review published in 1989, these drugs have not been used extensively in the United Kingdom or the United States. Large inquiries have also shown that the duration of prescription is quite different among countries. In European countries, maintenance therapy is frequently prescribed for several weeks to attempt to decrease the
\end{abstract}

number of acute episodes. In contrast, psychotropic drugs are less popular among European gastroenterologists than among American gastroenterologists. However, multidisciplinary approaches to the treatment of these patients are frequent, and such drugs are often prescribed by home physicians. The results of large surveys estimated the yearly cost of such treatments to be around US $\$ 850$. Patients with constipation and elderly patients with chronic disease receive more expensive treatments.

Key Words: Irritable bowel syndrome, Europe, Functional bowel disorders

\section{L'approche européenne au traitement du syndrome du côlon irritable}

RÉSUMÉ : Le syndrome du côlon irritable (SCI) se caractérise par un certain nombre de traits cliniques et englobe probablement tout un ensemble d'affections différentes. Le symptôme le plus fréquent signalé par les patients qui en sont atteints est la douleur abdominale, bien que chez certains, les troubles intestinaux prédominent. Les patients qui souffrent de diarrhée sont moins souvent examinés dans des centres de consultation en Europe continentale qu'au Royaume-Uni ou aux États-Unis. En revanche, les patients qui souffrent d'un SCI accompagné de constipation composent $80 \%$ de la population qui consulte dans ces centres. La physiopathologie du SCI repose sur de multiples facteurs. La plupart des thérapeutiques proposées pour le traitement des patients souffrant de SCI ont pour point de départ la présence de troubles de dysmotilité intestinale, le signe pathognomonique le plus fiable chez ces patients. Par conséquent, les antispasmodi- 
ques et les agents régulateurs de la motilité ont été couramment employés, seuls ou en association avec des adsorbants intestinaux (préparations à base d'argile) et avec des laxatifs ou des antidiarrhéiques. La plupart de ces médicaments ont été mis au point il y a plusieurs décennies et les études témoignant de leur efficacité n'ont pas le degré de rigueur que l'on exige désormais des essais contrôlés randomisés. Par conséquent, depuis la publication, en 1989, d'une revue synthèse complète et détaillée, ces médicaments ne sont plus très utilisés au Royaume-Uni ou aux États-Unis. De grandes enquêtes ont également démontré que la durée des ordonnances diffère considérablement d'un pays à l'autre. Dans les pays européens, le traitement d'entretien est souvent prescrit pendant plusieurs semaines pour tenter d'espacer les épisodes aigus. En revanche, les médicaments psychotropes sont moins populaires auprès des gastro-entérologues européens qu'auprès des gastro-entérologues américains. Toutefois, les approches pluridisciplinaires au traitement de ces patients sont fréquentes et des traitements médicamenteux sont souvent prescrits par les médecins traitants. Les résultats de grandes enquêtes ont estimé le coût annuel de ces traitements à environ 850 \$ US. Les patients qui souffrent de constipation et les patients âgés dont la maladie est chronique reçoivent les traitements les plus coûteux.
$\mathrm{I}_{\mathrm{ren}}^{\mathrm{r}}$ ritable bowel syndrome (IBS) is one of the most common reasons for referral of a patient to the gastroenterologist in Europe $(1,2)$. Its prevalence in the general population is estimated to be as high as $10 \%$. The pathophysiology of IBS is not completely understood and seems to be multifactorial. Attempts have been made to provide physicians with consensual definitions of functional bowel disorders, and the so-called 'Rome criteria' have been used since the past decade for defining patients in many studies (3). Although a consensus has been reached on the definitions, diagnosis and therapeutic strategies developed to manage IBS patients differ widely among countries. The aims of the present short review are to recognize the factors that influence these differential attitudes and to summarize the current therapeutic approaches to IBS in Europe.

\section{FACTORS INFLUENCING THE THERAPEUTIC DECISIONS OF PHYSICIANS}

Therapeutic decisions of physicians are based on a number of factors, including the knowledge that they have of the disease to be treated, the standards of practice laid out by scientific organizations, the pharmaceuticals commercially available in the country and the demands of the patients themselves. Epidemiological studies regarding the prevalence of IBS have not demonstrated dramatic differences among countries $(1,2,4)$. However, clinical experience has demonstrated a trend towards more constipated patients among IBS patients in the various countries of continental Europe, while diarrhetic patients seem to be more numerous in studies from the United Kingdom and the United States.

Another factor that may influence the mode of prescription is the legal environment, ie, the rules made by the regulatory authorities licensing drugs and the standard of practice published by scientific societies. While the United States Food and Drug Administration has not licensed a drug for the treatment of IBS in the United States, a number of drugs have been licensed in the various countries of the European Union, under various categories such as motility regulators and antispasmodics. The organization of health systems in the various countries may also have influenced the decisions of practitioners treating IBS, taking into account factors such as the reimbursement of payment for drugs, direct or controlled access to specialized care, and access to adjuvant therapeutics.

\section{DRUGS FOR THE TREATMENT OF IBS}

A survey of the literature shows that many drugs have been proposed for the treatment of IBS patients. Table 1 presents a list of drugs licensed in France for prescription to patients with IBS. Evaluation of the clinical benefit of drugs aimed at relieving abdominal pain in IBS patients has been very difficult because of the high rate of response to placebo. However, scientific evaluation of the pharmacodynamic and clinical effects of these drugs has been regarded as questionable in the recent scientific literature. A large review that took into account all studies published before 1988 demonstrated that none of the considered studies offered convincing evidence that any therapy is effective in treating IBS symptoms (5). The very negative conclusion drawn from this survey was based mainly on the poor methodology of outdated trials. However, this impression was not shared by other authors. In a meta-analysis of trials of smooth muscle relaxants in the treatment of IBS, Poynard et al (6) demonstrated the beneficial effect of some of these drugs on various symptoms. According to this overview, five drugs proved to be effective in relieving abdominal pain related to IBS $(64 \%$ improvement rate versus $45 \%$ for placebo, $\mathrm{P}<0.01)$ and improving the global impression of the patient (62\% improvement versus $37 \%$ for placebo, $\mathrm{P}<0.01$ ). In contrast, no significant improvement was demonstrated with these drugs for constipation and abdominal bloating. The five drugs that were shown to be effective in this meta-analysis were cimetropium bromide, pinaverium bromide, octilinium bromide, trimebutine and mebeverine.

These drugs are largely prescribed to patients with IBS, either for the short term treatment of pain attacks, for long term treatment or for maintenance treatment to prevent new attacks of pain (Table 1). Prescription for long term treatment is based on a number of studies that have evaluated the effects of such drugs over several months. A number of long term studies of trimebutine have demonstrated a significant benefit over placebo in many cases. A detailed description of the activity of trimebutine is available elsewhere $(7,8)$. One linear study of mebeverine, given orally $(200 \mathrm{mg}$ tid) to IBS patients, has been performed (9). In this study, mebeverine decreased significantly the intensity of abdominal pain over the period of treatment. However, in parallel, patients complained more frequently of bloating.

Together with smooth muscle relaxants, which are pri- 
TABLE 1

COPYRIGHT PULSUS GROUP

Pharmaceutical classes prescribed for the treatment of functional bowel disorders in European countries

Medications acting on smooth muscle (regulators of motility)

Atropinic antispasmodics

Atropine

Hyosciamine

Tiemonium

Nonatropinic antispasmodics

Pinaverium bromide

Phloroglucinol

Alverine citrate

Fenoverine

Smooth muscle regulators

Trimebutine

Mebeverine

Pinaverium bromide

Alverine citrate

Prokinetics

Metoclopramide

Domperidone

Cisapride

Medications with multiple active drugs

Librax (Hoffman-La Roche) (antispasmodic plus benzodiazepine)

Vésadol (Janssen-Cilag, Boulogne, France) (antisposmodic plus haloperidol)

Other digestive treatments

Laxatives

Antidiarrhetics

Intestinal adsorbents

Coal derivatives

Antacids

Antisecretory drugs

Pancreatic extracts

Psychotropic drugs

Anxiolytics

Antidepressants

Imipramine

Fluoxetine

marily aimed at relieving abdominal pain and bloating, laxatives or antidiarrheal agents and adsorbent agents such as clay derivatives are frequently prescribed. A large inquiry comprising 1302 patients with IBS, performed in 1992 in France, provided a better understanding of the drugs actually prescribed (10). This study included a nine-month follow-up of IBS patients, without any prescription forced by the protocol. Information was collected directly from patients through personal questionnaires mailed to the statistical centre. From this inquiry, it appeared that about $65 \%$ of patients were prescribed two or more drugs for IBS treatment and that smooth muscle relaxants comprised $63 \%$ of the total prescription of pharmaceuticals. Another remarkable feature is the high frequency of prescription of maintenance treatment. Indeed, the number of medications prescribed remained rather stable throughout the study. This maintenance therapy was aimed at preventing attacks of abdominal pain. It is noteworthy that in some European countries, patients clearly seek prescription of pharmaceuticals, which they consider to be the basis of their relationship with their

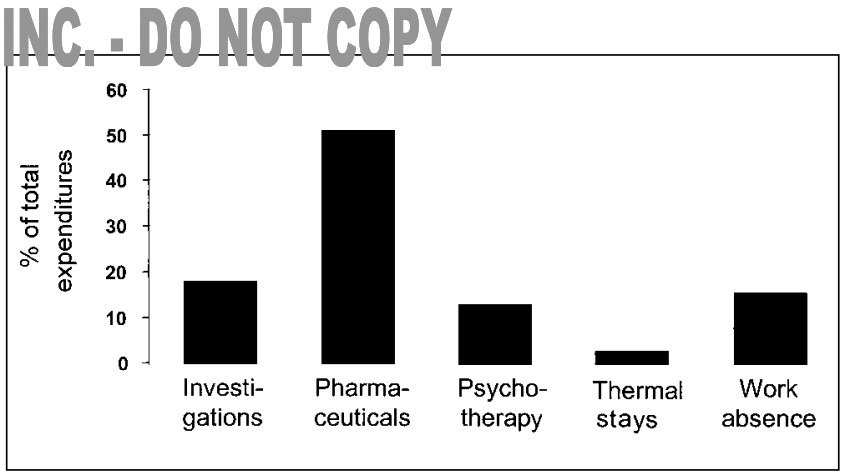

Figure 1) Distribution of health costs related to functional bowel disorders for diagnostic procedures, pharmaceuticals, psychological treatments and expenses due to absence from work

physician and a mandatory step for the management of their condition.

Hence, a number of studies have shown a clinical benefit of additional therapies. In a recent study, the prescription of thermal stays in some thermal springs in the Massif Central in France had a significant benefit on a group of IBS patients compared with a group of patients classically managed by gastroenterologists (personal communication). The combination of a thermal stay and conventional drug therapy was accompanied by significantly more marked improvement of quality of life, on both the global and personal scales of evaluation.

\section{COST OF IBS TREATMENT IN EUROPE}

Over the past year, the cost of health care has become one of the key issues of health policies in developed countries. The high prevalence of IBS justifies that consideration be given to the cost of its management. Recently, Talley et al (11) investigated the medical cost of IBS in Olmsted County, Minnesota. This study took into account only the charges due to hospital admittance, and laboratory and diagnostic procedures but did not calculate the cost of medications prescribed to out-patients. The overall medical cost of IBS was determined to be US $\$ 742$ compared with US $\$ 429$ for subjects with no gastrointestinal signs. In an inquiry conducted in France (10), the cost of IBS was calculated to be approximately US $\$ 800$ per year. This amount was distributed as follows: $18 \%$ for paraclinical investigations, $56 \%$ for pharmaceuticals, $17 \%$ for psychological treatments and $2.6 \%$ for other treatments. Absence from work and the related costs were estimated to account for $11 \%$ of this amount (Figure 1).

Health expenditures were influenced by a number of factors. Sex seemed to influence the level of expenditures because, on a global basis, women are considered to be 'more expensive' than men. Likewise, patients who have had the condition for more than 10 years cost significantly more than new patients (less than one year since diagnosis) (Figure 2). Symptoms presented by the patients are key determinants of the cost of their management. Factors include not only bowel habits but also the presence of intense abdominal pain at the time of entry into the study. Constipated patients 


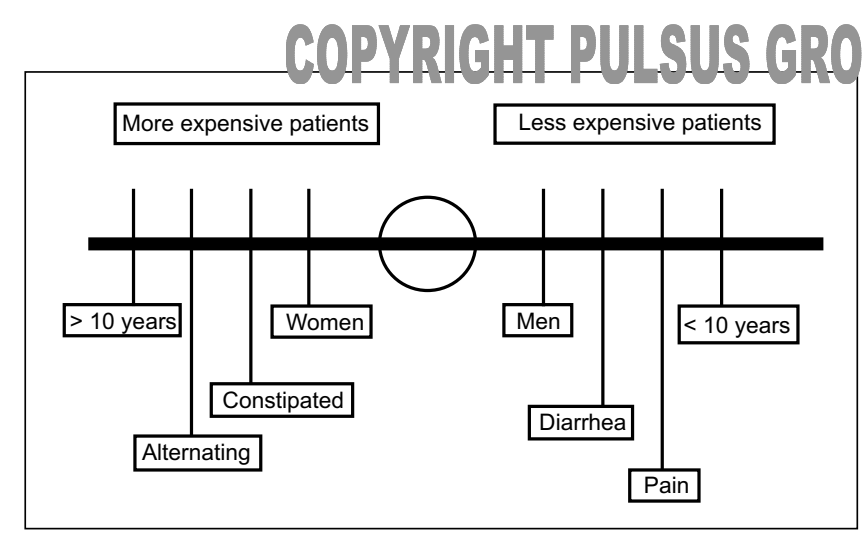

Figure 2) Relative level of cost of various categories of patients treated for functional bowel disorders. Average cost is approximately US850.00 per patient-year

appeared to spend more money for the management of their disease than diarrhetic ones. Patients with alternating diarrhea and constipation also spent more money than the average patient.

\section{CONCLUSIONS}

The European approach to IBS is marked by some prominent features that make it different from that in North America. Compared with the American approach, which has been recently summarized in a consensus report (12), the European approach is more frequently to prescribe multiple drug therapy and long standing maintenance treatments. This tendency is reinforced by the fact that quite a number of pharmaceuticals are licensed for this indication in the various European countries, while the United States Food and Drug Administration has not accepted any medication with an indication of functional bowel disorders. However, the pathophysiology of functional bowel disorders is multiple, and the therapeutic approach to these patients may benefit one of these pathophysiological features.

Finally, the clinical experience has proven that the key
$\mathrm{NC}=\mathrm{DO} \mathrm{NO} \mathrm{CO} \mathrm{PV}$

component in the management of functional bowel disorders is the quality of the patient-physician relationship. This component can be summarized by the following statement: The important feature is not the drug that you prescribe but rather the way that you prescribe it. And this is true everywhere!

\section{REFERENCES}

1. Bommelaer G, Rouch M, Dapoigny M, Delasalle P. Epidémiologie du syndrome de l'intestin irritable. Gastroenterol Clin Biol 1990;14:9C-12C.

2. Kay L, Jorgensen T, Jensen KH. The epidemiology of IBS in a random population: prevalence, incidence, natural history and risk factors. J Intern Med 1994;236:23-30.

3. Drossman DA, Thompson WG, Talley NJ, Janssens J, Funk-Jensen P. Identification of subgroups of functional gastrointestinal disorders. Gastroenterol Int 1990;3:159-72.

4. Drossman DA, Sandler RS, McKee DC, Louitz AJ. Bowel patterns among subjects not seeking healthcare. Use of a questionnaire to identify a population with bowel dysfunction. Gastroenterology 1982;83:529-34.

5. Klein KB. Controlled treatment trials in the irritable bowel syndrome: A critique. Gastroenterology 1988;95:232-41.

6. Poynard T, Naveau S, Mory B, Chaput JC. Meta-analysis of smooth muscle relaxants in the treatment of irritable bowel syndrome. Aliment Pharmacol Ther 1994;8:499-510.

7. Frexinos J, Fioramonti J, Buéno L. Effect of trimebutine on colonic myoelectrical activity in IBS patients. Eur J Clin Pharmacol 1985;28:181-5.

8. Delvaux $\mathrm{M}, \mathrm{W}$ ingate DL. Trimebutine: Mechanisms of action, effects on gastrointestinal function and clinical results. J Int Med Res 1997;25:225-46.

9. Delvaux M. A new mebeverine formulation in clinical practice. In: Denis P, ed. Irritable Bowel Syndrome. Berlin: de Gruyter, 1995:31-5.

10. Danquechin Dorval E, Delvaux M, Allemand H, Allouche S, Van Egroo LD, Lepen C. Profil et évolution du syndrôme de l'intestin irritable: étude épidémiologique nationale prospective chez 1301 consultants en gastro-entérologie suivis 9 mois. Gastroenterol Clin Biol 1994;18:145-50.

11. Talley NJ, Gabriel SE, Harsen WS, Zimmeister AR, Evans RW. Medical costs in community subjects with irritable bowel syndrome. Gastroenterology 1995;109:1736-41.

12. Drossman DA, Whitehead WE, Camilleri M. Irritable bowel syndrome: A technical review for practice guideline development. Gastroenterology 1997;112:2120-37. 


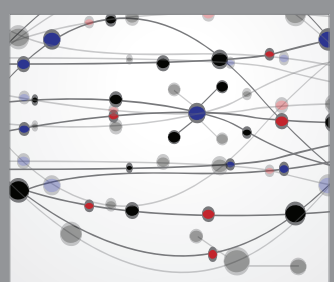

The Scientific World Journal
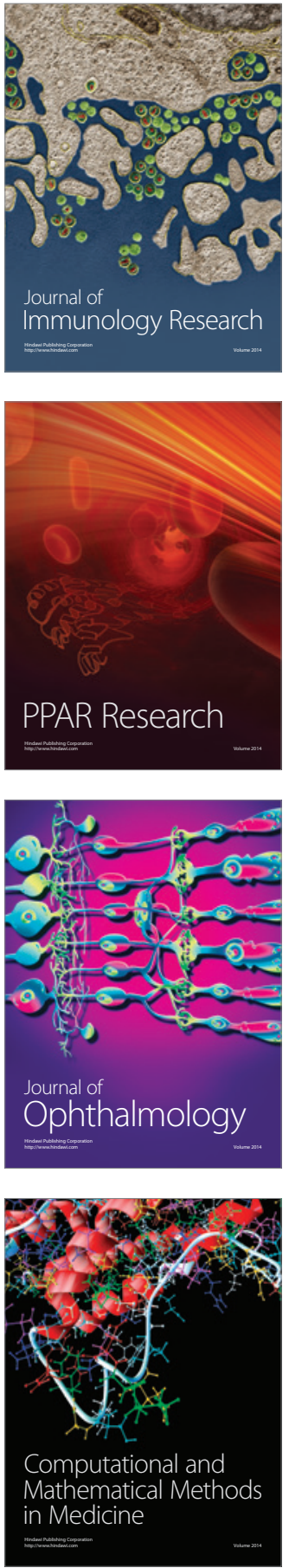

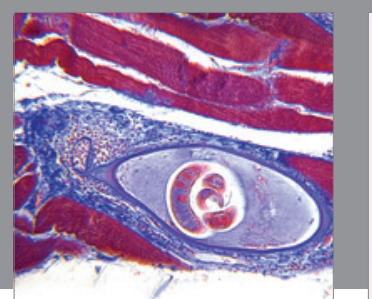

Gastroenterology Research and Practice

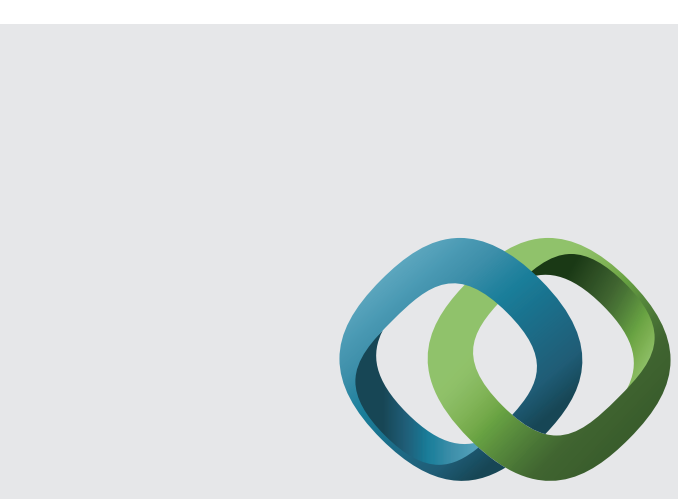

\section{Hindawi}

Submit your manuscripts at

http://www.hindawi.com
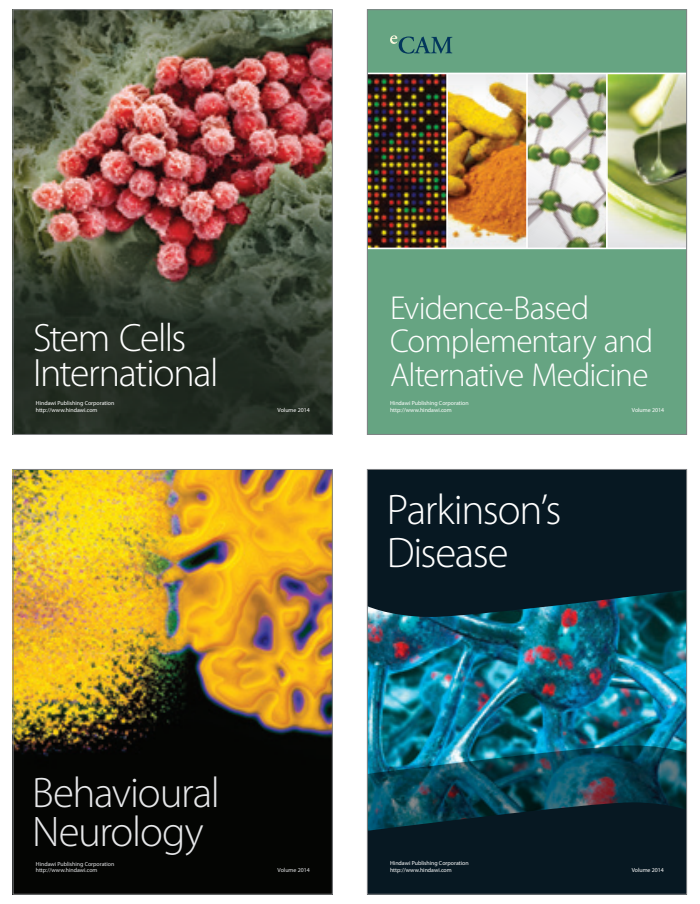
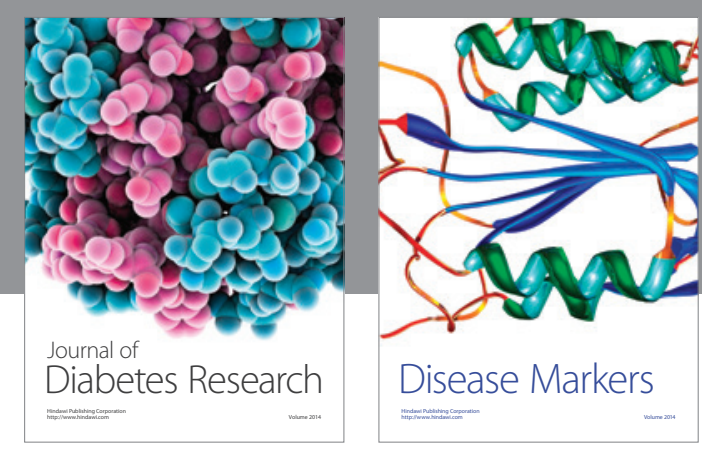

Disease Markers
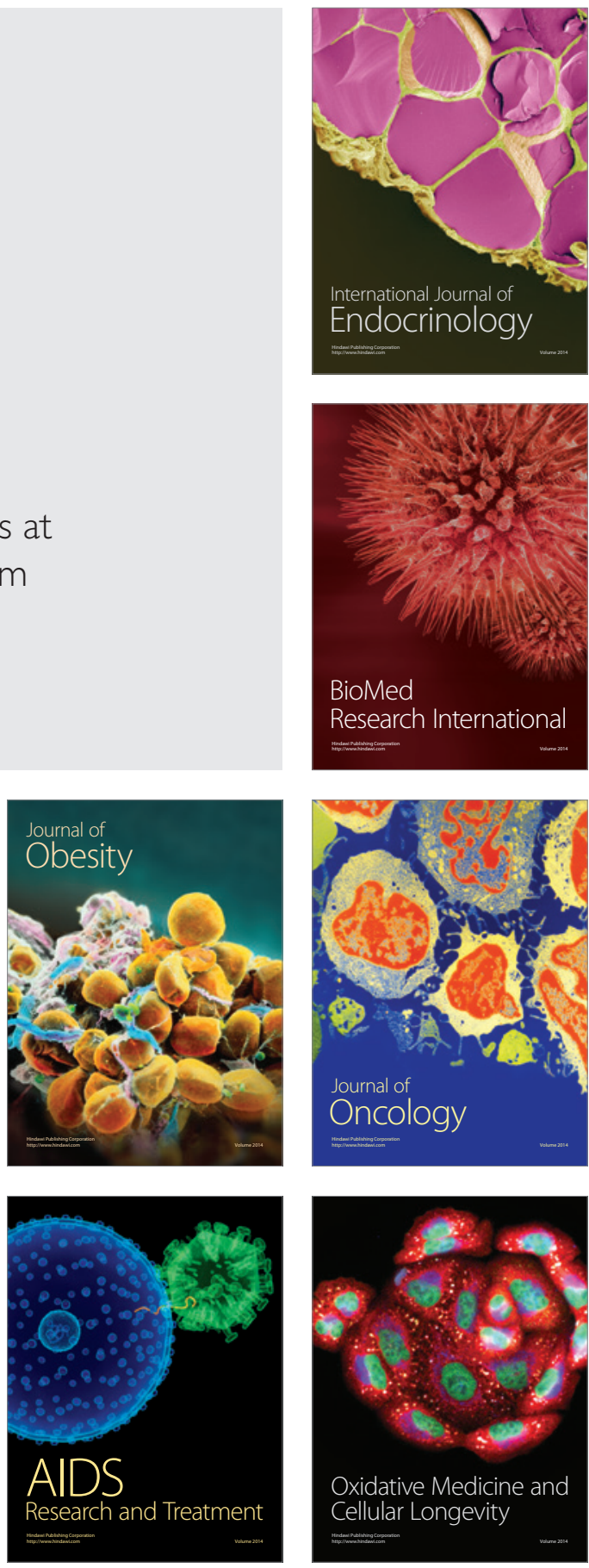